\title{
A Patente como Ferramenta de Construção de Estratégia Tecnológica: um estudo aplicado ao aproveitamento da fibra de coco
}

\author{
Patent as a Strategy Tool: a case study on coconut fiber use
}

\author{
Andrezza Lemos Rangel da Silva ${ }^{1}$ \\ Suzana Borschiver ${ }^{1}$ \\ Ricardo Carvalho Rodrigues ${ }^{2}$ \\ ${ }^{1}$ Universidade Federal do Rio de Janeiro, Rio de Janeiro, RJ, Brasil \\ ${ }^{2}$ Instituto Nacional da Propriedade Industrial, Rio de Janeiro, RJ, Brasil
}

\begin{abstract}
Resumo
A consolidação da economia baseada no conhecimento e o dinamismo do processo de desenvolvimento científicotecnológico tornam necessário o acompanhamento constante do estado da arte de um setor para que se possa mitigar o risco financeiro intrínseco à geração de inovação. Desse modo, a informação tecnológica tem sido cada vez mais utilizada como ferramenta de planejamento estratégico, subsidiando a tomada de decisão de instituições, empresas e, ainda, a formulação de políticas públicas, sendo a patente a fonte de informação mais relevante para esse fim. Para ilustrar o seu uso, o presente artigo apresenta um estudo de caso para aproveitamento da fibra de coco, um resíduo agroindustrial abundante no território nacional. Utilizando o método exploratório, no qual é feito levantamento bibliográfico para formulação de uma hipótese, foram analisadas 1.095 patentes concedidas, por meio das quais foi possível identificar relevantes oportunidades de aproveitamento do resíduo objeto deste estudo, sendo a principal delas a produção de itens para o setor agrícola.
\end{abstract}

Palavras-chave: Panorama de Patentes. Prospecção Tecnológica. Fibra de Coco.

\begin{abstract}
The consolidation of the knowledge-based economy and the dynamism of the scientific-technological development makes it necessary to study the state of the art of a sector, aiming to mitigate the financial risk of innovation process. Thus, technological information has been increasingly used as a strategic planning tool, supporting the decision-making of institutions, companies and the formulation of public policies, being the patent the most relevant information source for this purpose. To illustrate its use, this paper presents a case study on the use of coconut fiber, an abundant Brazilian's agro-industrial residue. Using the exploratory method, that is based on bibliographic research for thesis formulation, 1.095 granted patents were analyzed, through which it was possible to identify relevant opportunities for this waste use, where the main alternative is the production of items for agricultural sector.
\end{abstract}

Keywords: Patent Landscape. Technology Forecast. Coconut Fiber.

Área Tecnológica: Engenharia Química. Resíduos Agroindustriais. Gestão Tecnológica. 


\section{Introdução}

Segundo Trippe (2015), patentes são direitos de propriedade intelectual para proteção de uma invenção em territórios de jurisdição individual que pode ser concedida em contrapartida da divulgação da invenção. Uma vez que a patente concedida representa um direito de excluir terceiros de fazer, usar ou vender a invenção em uma jurisdição específica, há um valor de mercado associado a isso. As patentes são, às vezes, referidas como um "monopólio limitado", baseado em sua habilidade de prevenir competidores de entrar em um mercado ou usar uma tecnologia patenteada. Tanto pelo potencial de negócio quanto pelas implicações legais, entender quais organizações detêm patentes e quais áreas tecnológicas elas cobrem pode ter um significante impacto na elaboração de políticas e na tomada de decisão corporativa (TRIPPE, 2015).

A documentação de patentes é a mais completa entre as fontes de pesquisa. Estudos revelam que $70 \%$ das informações tecnológicas contidas nesses documentos não estão disponíveis em qualquer outro tipo de fonte de informação (INPI, 2015).

Os documentos de patente apresentam estrutura constituída das seguintes partes: folha de rosto, relatório descritivo, desenhos (se houver), reivindicações e resumo. A folha de rosto contém as chamadas informações bibliográficas (SOUZA; AGUIAR; MENDES, 2010). A maior parte das análises estatísticas, feitas a partir de patentes, tem como base a utilização de informações coletadas nesse campo do documento. Muitos desses campos contêm textos categorizados ou números e, consequentemente, são prontamente aplicáveis a análises. Os campos bibliográficos frequentemente utilizados na análise são requerente/depositante (Applicant/Assignee); inventor; datas; classificações; e citações.

No contexto do uso das patentes como fonte de informação tecnológica, o Solicitante/Depositante (Applicant/Assignee) representa o dono da patente e com quem as negociações pelos direitos associados à invenção terão que ser conduzidas. Estudando esse campo, por exemplo, identificam-se investidores em uma área técnica específica. Sob a ótica das redes de relacionamentos frequentemente aplicadas para identificar colaboradores para uma determinada área de conhecimento. Já o inventor representa a pessoa ou as pessoas que são responsáveis pelo esforço intelectual associado à invenção. Uma análise de rede de relacionamentos é aplicada neste caso para identificar colaborações entre diferentes inventores ou grupos e instituições para as quais eles trabalham (TRIPPE, 2015).

Passando aos dados referentes a datas, estas correspondem a marcos temporais significativos no ciclo de vida da solicitação de patentes. Os três mais importantes são a data de prioridade (priority date), a de depósito (filling date) e a de publicação (publication date).

A data de prioridade (ou datas, se a prioridade de várias solicitações anteriores for reivindicada) corresponde à data de depósito de um pedido anterior se o requerente reivindicar a prioridade desse pedido anterior. Isso é importante, pois pode determinar a relevância do estado da técnica se certas condições são conhecidas. Vale mencionar que essa prática pode servir para identificar documentos que foram publicados em diferentes países e idiomas, mas se referem à mesma invenção ("Família de patentes").

A data de publicação é a data em que o documento é divulgado. Os pedidos de patente são publicados 18 meses após a data de apresentação ou a data de prioridade mais antiga na 
maioria das autoridades emissoras de patentes. No caso das patentes concedidas, a data de publicação coincide com a data de concessão.

Essas datas representam o tempo associado ao desenvolvimento ou patenteamento de uma invenção e são utilizadas para analisar tendências. O estudo das datas de depósito e prioridade é uma indicação de quando as invenções foram desenvolvidas e quanto tempo demorou para as melhorias e modificações começarem. A data de publicação é menos útil para esse propósito. Em particular, a data de concessão é mais um indicador de tempo entre a solicitação e a concessão da patente (TRIPPE, 2015).

No tocante a classificações, a Classificação Internacional de Patentes (CIP) deve ser vista como uma ferramenta importante para acessar a informação desejada e é utilizada internacionalmente para indexação de documentos de patente de invenção e modelo de utilidade (DUPIN; SPRITZER, 2004).

Essa classificação foi estabelecida pelo Acordo de Strasbourg em 1971 e provê um sistema de linguagem independente de símbolos para a categorização dos documentos de acordo com as diferentes áreas tecnológicas às quais eles pertencem. Uma nova versão da CIP entra em vigor a cada ano em $1^{\circ}$ de janeiro (WIPO, 2018).

Durante o processo de patenteamento, um examinador irá buscar o estado da arte relacionado à novidade ou um passo inventivo relacionado à invenção. Quando referências desta natureza são descobertas, elas são citadas no documento durante diferentes estágios de publicação, usualmente, em um relatório de busca que acompanha o documento.

Assim, as citações representam uma potencial relação entre duas invenções. O seu estudo permite, por exemplo, identificar a origem da invenção que pode ter tido um impacto maior no desenvolvimento de uma tecnologia (TRIPPE, 2015).

Para ilustrar a aplicação dos conceitos expostos, o presente artigo apresenta um estudo de caso sobre o aproveitamento da fibra de coco.

\subsection{Contextualização: a fibra de coco}

O Brasil se destaca na produção agrícola, sendo este um dos setores econômicos mais estratégicos para o país. A grande participação e o forte efeito multiplicador do complexo agroindustrial no Produto Interno Bruto (PIB), o alto peso dos produtos de origem agrícola (básicos, semielaborados e industrializados) na pauta de exportações e a contribuição para o controle da inflação são exemplos da importância da agricultura para o desempenho da economia brasileira (IPEA, 2012). Diante do desempenho do setor, é possível perceber o grande potencial deste em relação à geração de resíduos, que está associada ao desperdício no uso de insumos, às perdas entre a produção e o consumo e aos materiais que, gerados ao longo da cadeia agroindustrial, não possuem valor econômico evidente (ROSA et al., 2011).

Um resíduo agrícola abundante no território nacional é a fibra de coco verde, devido à sua alta produção e ao consumo da fruta no país (MARTINS, 2013). É importante destacar o avanço dessa cultura no Brasil: em 1990, o país ocupava a $10^{a}$ posição no ranking mundial, com uma produção ao redor das 477 mil toneladas de coco (MARTINS; JESUS JR., 2014). Atualmente, o país é o quinto maior produtor mundial com uma produção de, aproximadamente, 2,3 milhões de toneladas em 2017 (FAOSTAT, 2020). A literatura reporta que de $80 \%$ a $85 \%$ do peso bruto 
do coco verde é descartado (PEREIRA, 2012). Considerando a produção brasileira de 2017 de 2,3 milhões de toneladas, cerca 1,8 milhão de tonelada é considerado resíduo e, como tal, é disposto em lixões, vazadouros, encostas e até mesmo em aterros sanitários, passando por um processo de decomposição causado pela ação de micro-organismos, que fazem a biodigestão da matéria orgânica. Assim, outro problema causado pelo descarte desse resíduo é a emissão de metano, um dos gases mais importantes do efeito estufa (PEREIRA, 2012). Vale a pena ressaltar que a casca do coco verde é um material de difícil decomposição, levando mais de oito anos para se decompor (SEBRAE NACIONAL, 2016).

Em botânica, o fruto do coqueiro é classificado como uma drupa fibrosa, ou seja, se mantém fechado durante toda a sua vida, possui uma camada fibrosa (mesocarpo), uma camada lenhosa (endocarpo), com três poros de germinação localizados externamente, no epicarpo, e, internamente, no albúmen sólido (copra) (MARTINS, 2013). A Figura 1 mostra as principais partes do fruto do coqueiro.

Figura 1 - Corte longitudinal do coco

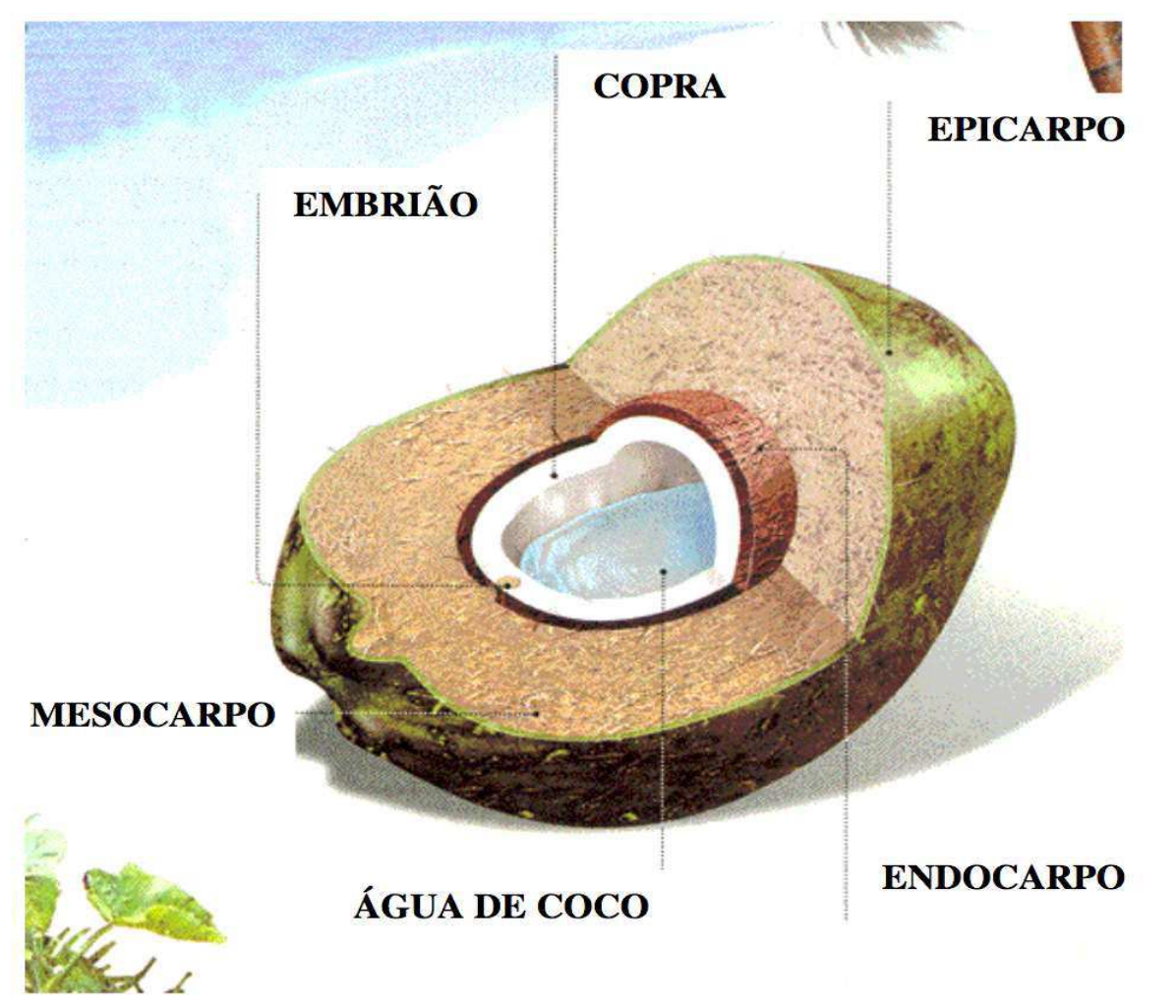

Fonte: Mattos et al. (2014)

Na estrutura do coco, considera-se como resíduo do agronegócio a fração constituída pelo mesocarpo, que é a parte espessa e fibrosa do fruto, pelo exocarpo ou epicarpo, que constitui a epiderme, e pelo endocarpo, que no fruto imaturo ainda não se apresenta tão duro e rígido como no coco maduro (MATTOS et al., 2014).

A fibra de coco extraída do mesocarpo, parte espessa fibrosa do fruto, apresenta uma elasticidade superior a outras fibras vegetais, além de uma elevada capacidade de resistir à umidade e a altas variações nas condições climáticas. É constituída de materiais lignocelulósicos, sendo suas principais características a baixa densidade, a boa flexibilidade no processamento e a 
facilidade de modificação perante agentes químicos, além de ser fonte de recursos renováveis, biodegradáveis e não abrasivos (CASTILHOS, 2011).

Diante do exposto, ressalta-se que o objetivo geral do presente trabalho é identificar as principais tendências tecnológicas relacionadas ao aproveitamento da fibra de coco, desenvolvidas em âmbito mundial por meio da construção de um panorama de patentes, seguindo o referencial metodológico de análise do padrão internacional desenvolvido pela World Intellectual Property Organization (WIPO), e divulgado por meio do guia "Guidelines for Preparing Patent Landscape Reports".

\section{Metodologia}

A metodologia de pesquisa selecionada para o presente estudo foi a chamada Pesquisa Exploratória. Esse tipo de pesquisa tem como objetivo proporcionar maior familiaridade com o problema, com vistas a torná-lo mais explícito ou a construir hipóteses. A grande maioria dessas pesquisas envolve: (a) levantamento bibliográfico; (b) entrevistas com pessoas que tiveram experiências práticas com o problema pesquisado; $e$ (c) análise de exemplos que estimulem a compreensão. Essas pesquisas podem ser classificadas como: pesquisa bibliográfica e estudo de caso (GERHARDT; SILVEIRA, 2009).

A primeira etapa da metodologia consistiu na seleção da ferramenta de busca mais adequada ao propósito do Patent Landscape.

Usualmente, os trabalhos acadêmicos privilegiam o uso de bases de dados gratuitas para acesso a informações de patentes. Para o presente trabalho, optou-se por se utilizar os recursos do site Patent Inspiration (https://www.patentinspiration.com). Trata-se de uma ferramenta paga de busca e de análise que pode ser utilizada para identificação de tendências tecnológicas de um determinado setor ou domínio. A ferramenta foi selecionada por apresentar melhor relação custo x benefícios e não necessitar de assinatura corporativa para acesso à informação, pois há a opção de assinatura individual, com possibilidade de descontos para estudantes.

A segunda etapa da metodologia consistiu em selecionar as palavras-chave pertinentes ao tema e propor o cruzamento entre elas para busca na ferramenta escolhida. Com base na literatura, foram identificados os seguintes termos referentes à fibra de coco: "coconut mesocarp", "coir", "coconut fiber" e "coconut lignin". Utilizando o recurso find related terms existente no site, adicionou-se à lista os termos "coconut fibre" e "coconut fibrous husk".

A primeira proposta de cruzamento dos termos identificados teve a seguinte estrutura: (coconut AND (fiber or fibre or mesocarp or (fibrous and husk) or lignin)) or coir).

Como parâmetros de busca, optou-se por localizar os termos no título ou no resumo, de forma a garantir a especificidade da busca e resultados mais assertivos; habilitou-se a ferramenta de "stemming" que reduz um dado termo de busca a sua raiz mais básica, ou seja, habilita a busca por termos adjacentes que tenham a mesma raiz; busca em todo espaço temporal ofertado pela base (a partir de 1900); retornando apenas um resultado por família de patentes; separando patentes concedidas e solicitadas, pois o foco principal deste trabalho é a análise das patentes concedidas.

Nesta etapa, foram obtidos 1.570 documentos. Entretanto, de forma amostral foram analisados manualmente alguns resultados e percebeu-se que, com essa estrutura, apesar de 
"coconut" e pelo menos um dos termos após o booleano AND ter sido localizado, muitas vezes, não estavam relacionados na mesma sentença, o que prejudica a pertinência da patente ao escopo do presente estudo.

Sendo assim, uma nova estrutura de busca foi criada, utilizando os mesmos parâmetros anteriores: ("coconut fiber" OR "coconut fibre" OR "coconut mesocarp" OR (coconut AND fibrous AND husk) OR "coconut lignin” OR coir). Como resultado, foram obtidos 1.095 patentes concedidas, que serão o objeto de análise do presente estudo.

\section{Resultados e Discussão}

Considerando os campos bibliográficos da patente, o primeiro a ser analisado foi a data de depósito. O Gráfico 1 apresenta a distribuição dos documentos ao longo do tempo, isto é, a atividade patentária. Por meio dele é possível observar um perfil de crescimento dos depósitos até o ano de 2013, quando se tem um ponto de inflexão, coincidindo com uma queda da produção mundial de coco, conforme explicitado no Gráfico 2. Segundo Burton (2017), apesar dos esforços para garantir que a expansão do setor chegue aos pequenos produtores, a falta de investimento na sustentação da produtividade da terra de cultivo de coco, em grande parte devido aos altos custos associados, implica que algumas fazendas estão produzindo $75 \%$ menos frutas do que há 30 anos. O problema da oferta insuficiente para atender ao aumento da demanda não é ajudado pelo fato de que muitas das árvores que produzem cocos têm mais de 50 anos, 20 anos após seus anos de produção. Várias plantações em toda a Ásia estão experimentando crescimento zero, e algumas estão até cessando a produção à medida que seus agricultores mudam seu foco para a produção de dendê.

Gráfico 1 - Atividade patentária considerando a data de depósito (1998-2018)

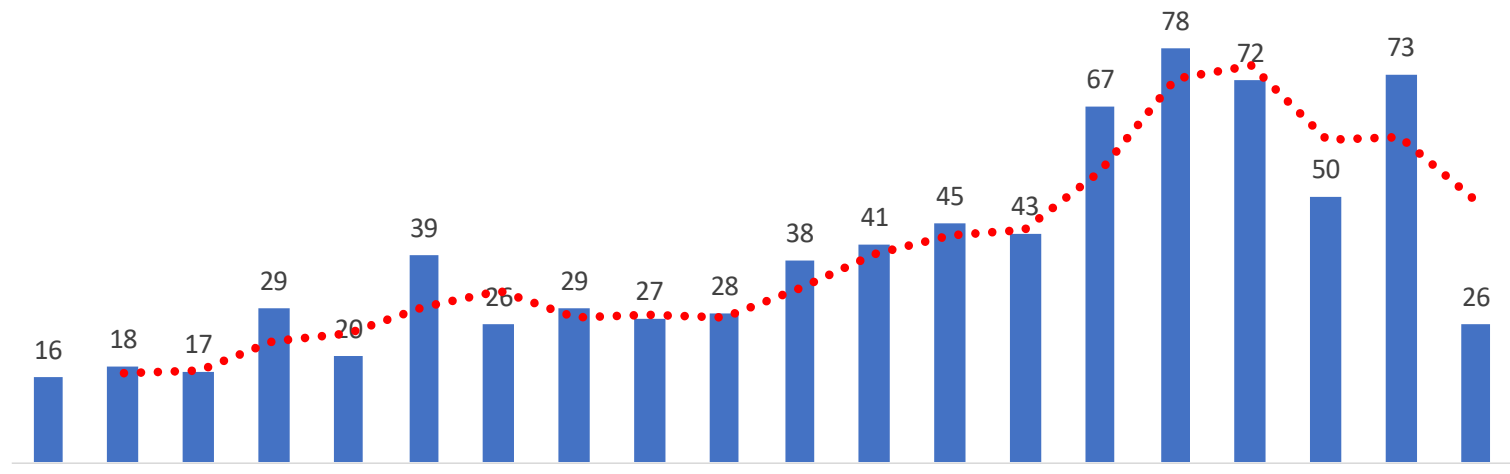

Fonte: Elaborado a partir de Patent Inspiration (2018) 
Gráfico 2 - Produção mundial de coco (1998-2018)

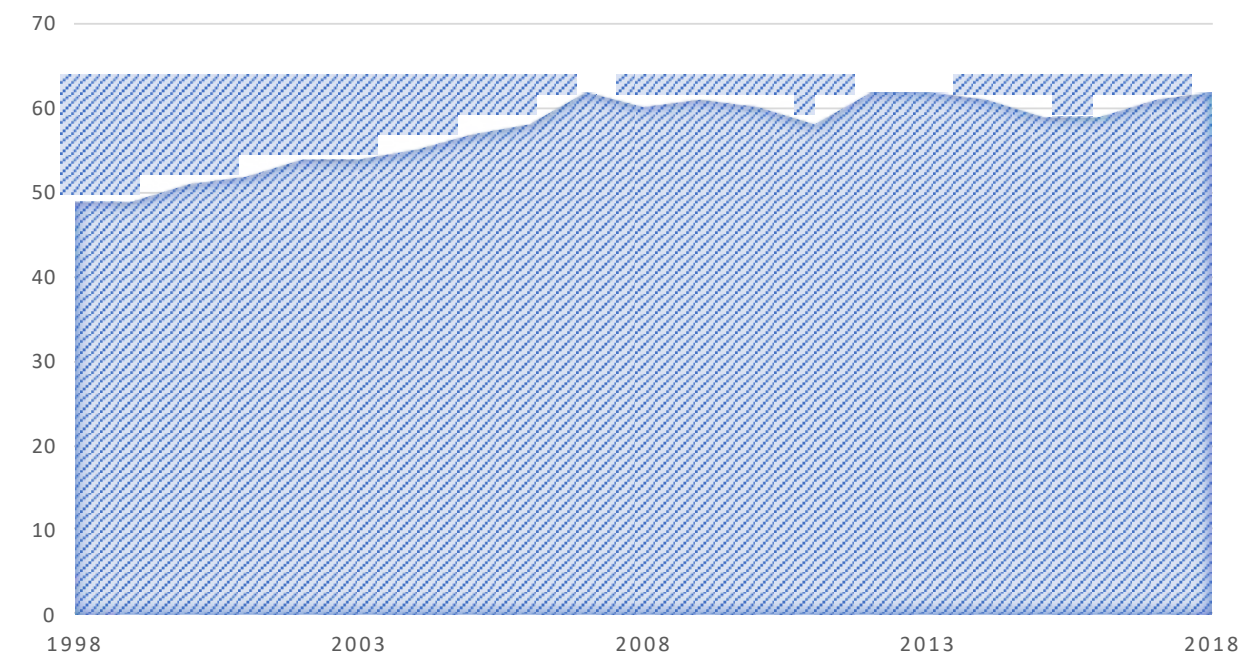

Fonte: Elaborado a partir de Faostat (2020)

Por meio da análise do Gráfico 1, é possível também fazer inferências a respeito do grau de maturidade da tecnologia relacionada ao uso da fibra de coco. O gráfico apresentado pode ser analisado como uma curva de evolução tecnológica. Considerando que, a partir de 2016, a curva apresenta uma tendência de decréscimo, permitindo inferir que o segmento tecnológico pode estar próximo a seu estado de maturidade. Vale destacar que, para uma análise mais precisa, é importante acompanhar o desenvolvimento tecnológico por mais alguns anos a partir de 2018, pois a tendência observada pode estar sendo causada por algum aspecto da conjuntura socioeconômica, por exemplo. Além disso, a distribuição temporal isoladamente não é suficiente para definir o grau de maturidade da tecnologia.

Outro dado que pode embasar a inferência anterior é a análise da curva temporal de patentes depositadas (applied patents). Repetindo-se a metodologia de busca proposta, dessa vez para os documentos ainda não concedidos, foi possível obter os dados do Gráfico 3. Mais uma vez observa-se uma curva com perfil crescente, com maior concentração no biênio 2016-2017, e uma aparente queda em 2018 (que foi analisado até agosto, quando foi executada a busca). Apesar dessa aparente queda, vale a pena destacar que é possível que existam documentos deste ano que, na época de execução da busca, estavam sob período de sigilo (18 meses).

Gráfico 3 - Atividade patentária considerando a data de depósito (1998-2018) - Applied Patents

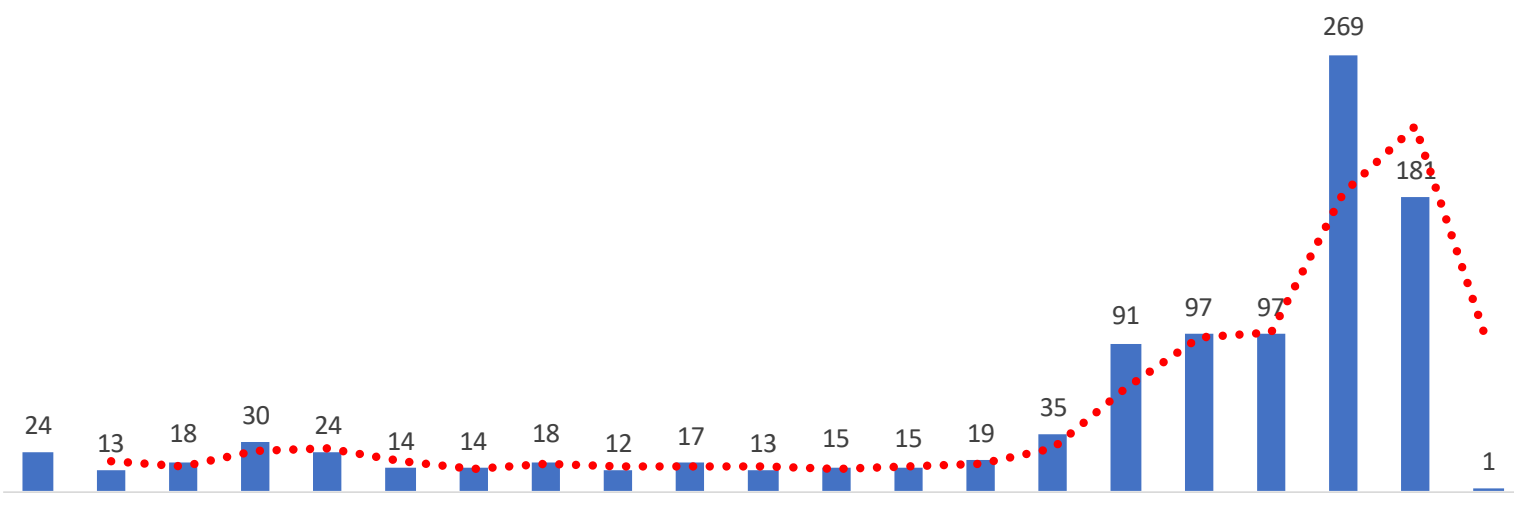

Fonte: Elaborado a partir de Patent Inspiration (2018) 
Outro aspecto relevante a ser analisado a partir dos dados bibliográficos das patentes é a região de origem da inovação. O Gráfico 4 apresenta os 10 principais países dos depositantes das patentes em análise. Por meio dela é possível observar que há uma grande concentração de depósitos provenientes de países asiáticos, o que é esperado visto que o ranking de produção mundial desse fruto é liderado por essa região (Indonésia, Filipinas e Índia). Além disso, esses países fazem parte do grupo dos 20 países com maior Índice de Inovação, de acordo com o relatório do Índice de Inovação Global (IIG) 2017, publicado pela OMPI e pela Universidade de Cornell (WIPO; INSEAD, 2017). Entre os países representados no Gráfico 4, observa-se que o país com maior volume de patentes concedidas é a China (204 documentos). Vale mencionar que o país se encontra entre os 10 países com maior número de depósitos de patentes em 2018, ranking este liderado pelos Estados Unidos, segundo o Annual Report 2018, publicado pelo European Patent Office.

Gráfico 4 - Distribuição das patentes por país de origem do depositante - 10 principais países

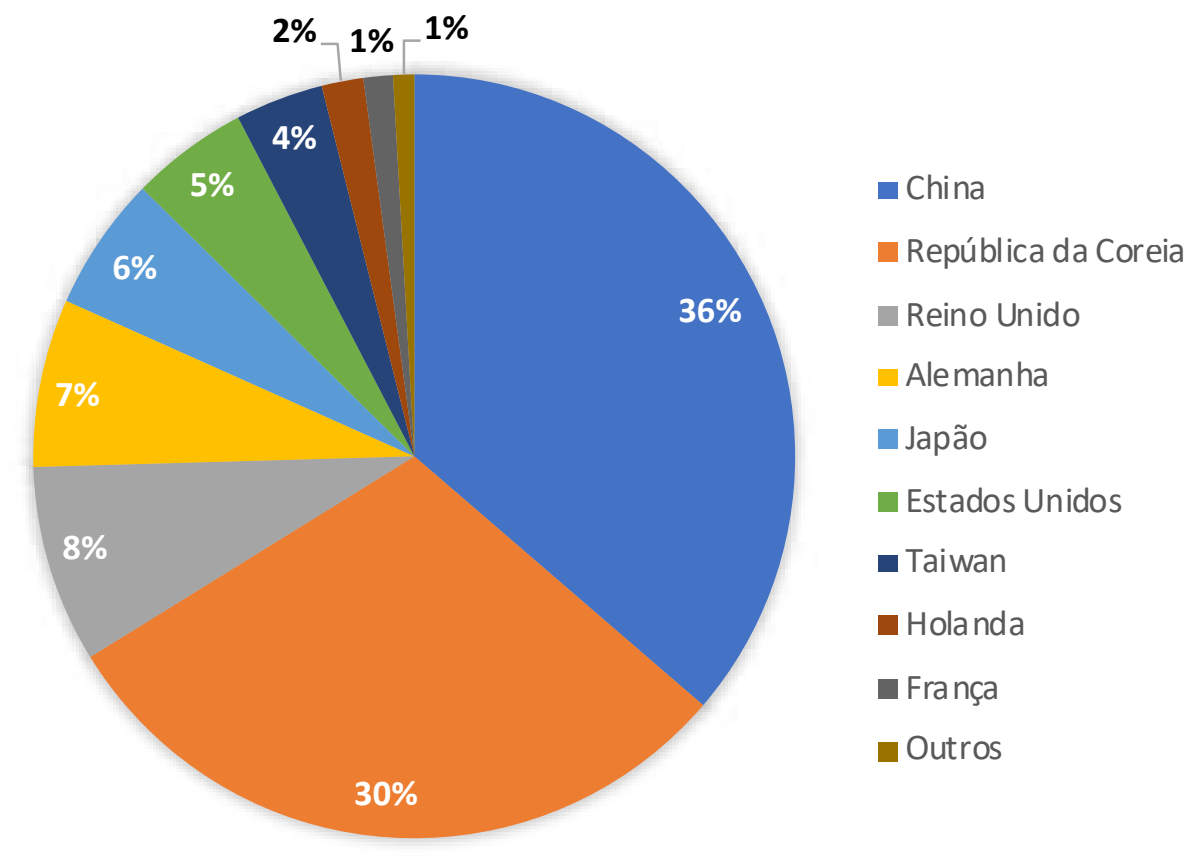

Fonte: Elaborado a partir de Patent Inspiration (2018)

Ainda sobre o país de origem do depositante, vale destacar que, apesar de o Brasil fazer parte do ranking de maiores produtores de coco, não foram identificadas, no universo analisado, patentes concedidas sobre o aproveitamento da fibra.

Com objetivo de observar se há algum movimento brasileiro, no âmbito internacional, para o desenvolvimento de tecnologias nesse segmento, mais uma vez repetiu-se a metodologia de busca selecionando como parâmetro patentes ainda não concedidas (applied patents). Considerando os 10 principais países neste caso, ainda não se observa a participação do Brasil. 
Entretanto, ampliando o ranking para os 20 maiores depositantes, o país é localizado no final da lista, com três patentes, notando-se mais uma vez a concentração de documentos na região da Ásia. O resultado pode ser observado no Gráfico 5. O Brasil foi agrupado junto à Áustria, Holanda, Bélgica e Itália no grupo "Outros".

Gráfico 5 - Distribuição das patentes por país de origem do depositante (Applied patents) - 20 principais países

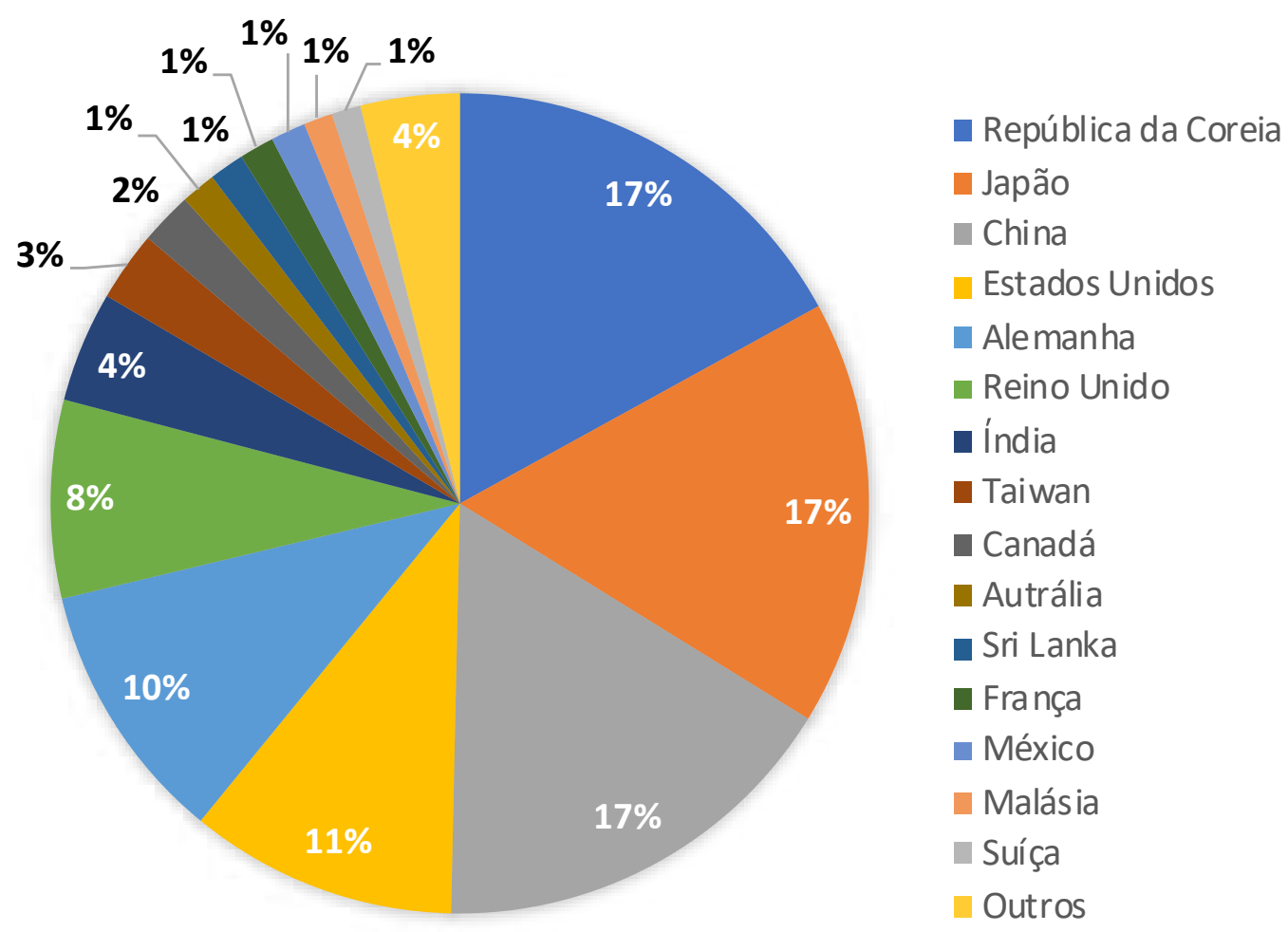

Fonte: Elaborado a partir de Patent Inspiration (2018)

Para agrupar os documentos sob a ótica tecnológica, o campo que será analisado é a Classificação Internacional de Patentes (CIP), identificando a natureza das invenções e as principais tendências dos últimos anos.

Conforme descrito na introdução deste artigo, a CIP é um código de indexação de documentos de patentes utilizado internacionalmente, categorizando os documentos de acordo com as áreas tecnológicas às quais pertencem.

Para o universo das 1.095 patentes concedidas obtidas, o Gráfico 6 apresenta a distribuição dos documentos considerando os 10 grupos principais de maior recorrência nas patentes. 
Gráfico 6 - Distribuição das Patentes por Grupo Principal - CIP

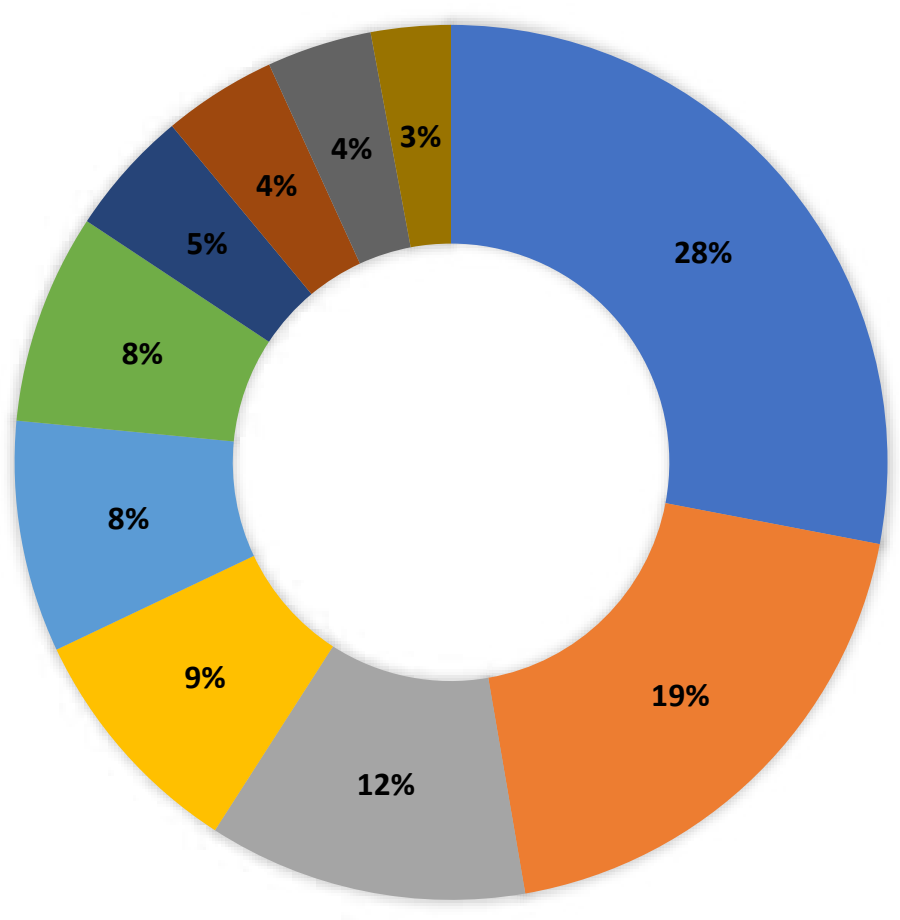

- A47C27/00 - Molas, est ofados ou colchões pneumáticos

A01G1/00 - Horticultura

E02D17/00 - Escavações

A01G31/00 - Cultivo sem uso de solo, p. ex. hidroponia

- A01G9/00 - Receptáculos, estufas ou casas de vegetação para horticultura

E E2B3/00 - Trabal hos de engenharia relativos ao controle ou à uso de cursos d'água

D04H1/00 - Não tecidos formados única ou principalmente por fibras curtas ou por fibras similares relativamente curtas

- B32B9/00 - Produtos em camadas que compreendam essencial mente uma substância em particular, não abrangida pelos grupos

- A47C23/00 - Colchões de molas com armação rígida ou constituind o parte do estrado, p. ex. cama box; Bases de divãs; Estrados de ripas

- C05G3/00 - Misturas de um ou mais fertilizantes com substâncias sem atividades especificamente fertilizantes

Fonte: Elaborado a partir de Patent Inspiration (2018)

De acordo com Gráfico 6, o primeiro aspecto que chama atenção é o fato de que os grupos de maior recorrência estão na Seção A - Necessidades Humanas - denotando um possível direcionamento para a aplicação final da fibra de coco, em detrimento da melhoria dos processos de sua obtenção. Lembrando que a estratégia de busca adotada foi generalista, permitindo a aquisição de documentos de diferentes naturezas, ou seja, o escopo não foi restrito a nenhum aspecto específico do processo, de forma a se ter um panorama geral do estado da arte.

Com 28\% (180 patentes), tem-se o Grupo Principal A47C27/00 referente a Molas, estofados ou colchões pneumáticos especialmente adaptados a cadeiras, camas ou sofás. Analisando-se as patentes desse grupo, identificou-se que se referem à construção de colchões contendo fibra de coco em suas camadas. Um exemplo dessa categoria é o modelo de utilidade chinês publicado em 2017 CN205923539U - Utensil traditional chinese medicine stratum society type mattress, que utiliza a fibra de coco como leito de sustentação das molas. Outro exemplo é o trazido pelo documento chinês de 2018 CN207186409U - Coconut fiber mattress, que trata da construção de um colchão pela sobreposição de camadas de fibra de coco macia e rígida para atingir a rigidez ideal para o corpo humano e para evitar infestação por insetos.

O segundo Grupo em relevância é o $\mathrm{A} 01 \mathrm{G1} / 00$, com 124 patentes (19\%), que se refere à Horticultura; Cultivo de Vegetais, Flores, Arroz, Frutas, Vinhas, Lúpulos ou Algas; Silvicultura; Irrigação, no qual a fibra de coco é aplicada em mistura para meio de cultivo de plantas, como é o caso da patente CN106212001A - Ilex kudincha seedling cuttage reproduction method, em que a fibra de coco é misturada com lama amarela, areia e esterco para servir de meio de reprodução de mudas de Ilex kudincha, ou ainda o documento CN205005535U - Planting technique system suitable for curved surface roof, que apresenta uma técnica de plantio de mudas 
em superfícies curvas (como telhas) e utiliza a fibra de coco como meio de cultivo e sustentação da planta. Há também a aplicação como manta de proteção de corpos hidrográficos, como no modelo de utilidade CN205024644U - Modular ecological revetment structure.

O Grupo E02D17/00, com 76 patentes, diz respeito a Escavações; Guarnição das bordas das escavações; Construção de aterros. Neste, tem-se como exemplo o modelo de utilidade CN205857209U - Ecological bank protection of soil and water conservation, em que colunas de fibra de coco são utilizadas como meio de evitar erosão do solo e perda de água. Outro exemplo é a patente coreana KR20170054786A - A Coir net weaving machine, que apresenta a construção de uma máquina para tecelagem de fios à base de fibra de coco, necessária para tecer as mantas de proteção do solo.

O Grupo A01G31/00 (57 patentes), referente a Cultivo sem uso de solo, por exemplo, Hidroponia, tendo como amostra os documentos GB2543968A - Coir substrate and apparatus and method for the production thereof, que apresenta um método de produção de substrato de fibra de coco, e AU2016101963A4 - Hydroponic Container, que apresenta a construção de um recipiente para cultivo hidropônico, contendo fibra de coco compactada como meio de cultivo.

Por fim, no grupo A01G9/00 (55 documentos), que diz respeito a Cultivo em receptáculos, estufas ou casas de vegetação; Bordadura para canteiros, gramados ou similares, tem-se o documento CN105659977A - Environmental-protection ecological vegetation carpet by utilization of municipal sludge, que apresenta a formulação de um "tapete" ecológico de vegetação que utiliza fibra de coco em uma de suas camadas.

\subsection{O Caso das Patentes Brasileiras}

Conforme citado anteriormente, uma vez que não foram identificados documentos brasileiros nos resultados obtidos para patentes concedidas, a mesma metodologia foi repetida para o grupo de patentes solicitadas (applied patents). Nesse momento, foram identificadas três solicitações brasileiras:

\section{Patente WO2017049373A1 - Thermophotovoltaic (tpv) solar panel with hybrid} coconut fiber, solicitada por uma pessoa física, que apresenta uma unidade solar híbrida monolítica capaz de gerar energia solar a partir de duas fontes solares (fotovoltaica e térmica) ao mesmo tempo e instantaneamente, tal invenção é desenvolvida usando-se fibra de coco e silício.

[Códigos CIP: H02S10/30 - Sistemas termofotovoltaicos (células fotovoltaicas especialmente adaptadas para conversão ou meios de detecção para radiação infravermelha [IR] H01L 31/00; dispositivos termoelétricos H01L 35/00)/H02S40/44 - Meios para utilizar energia do calor, por exemplo, sistemas híbridos que produzem água aquecida e eletricidade ao mesmo tempo (diretamente associados à célula fotovoltaica [PV] ou integrados à célula PV].

\section{Patente WO2015058268A1 - Method for producing natural-latex-insulated} coconut-fibre soles and inputs for the footwear industry, também solicitada por pessoa física, apresenta um método para a produção de solados e insumos de fibra de coco com látex natural para a indústria calçadista, compreendendo uma folha de fibra de coco e a sola de látex natural, ambos cortados no modelo do calçado e forrados com folhas de couro para garantir a durabilidade do calçado. 
[Códigos CIP: A43B1/02 - Calçados feitos de fibras animais ou fibras de plantas ou de tecidos fabricados com as mesmas/A43B1/10 - Calçados feitos de borracha/A43B7/00 - Calçados com dispositivos higiênicos ou sanitários/A43B17/00 - Palmilhas para inserção, por exemplo, enchimentos ou encaixes para serem fixadas ao sapato após a gáspea ser agregada].

\section{Patente US2014026258A1 - Bacterial formulation which can be used for biolo- gically controlling plant diseases and promoting plant growth, solicitada pela Embrapa juntamente com o inventor. A patente refere-se a uma formulação bacteriana em materiais de fibra vegetal (preferencialmente fibra de coco) que podem ser incorporados em solos e para tratamento de sementes, bem como em nutrientes em sistemas hidroscópicos, para promoção de crescimento de plantas e/ou controle biológico de doenças.}

[Códigos CIP: A01N 63/04 - Fungos microbiais; Substâncias produzidas por meio destas ou obtidas a partir destas/A61K 35/74 - Bactérias (uso terapêutico de proteínas de origem bacteriana)].

O incipiente movimento do Brasil no cenário internacional não significa o desinteresse nacional em desenvolvimentos tecnológicos para o setor. Executando-se uma busca na base de patentes do Instituto Nacional da Propriedade Industrial (INPI), utilizando-se a expressão "Fibra de Coco" para busca no resumo, é possível identificar 99 processos, sendo o mais recente de 2017. Destaca-se neste grupo as patentes de invenção PI 0505824-4 A2, depositada em 2005 por Fortaleza Indústria e Comércio e Serviços de Máquinas Agrícolas Ltda., que apresenta uma esteira de alimentação (1), uma máquina esmagadora (2), uma prensa (3) e uma máquina classificadora (4), capazes de esmagar e de prensar o coco verde, e, ainda, de classificar a fibra produzida de forma automatizada, sem que seja necessária a alimentação manual em qualquer uma das fases, com máquinas mais simples e dispostas em série, uma fixada na outra, por meio de balizadores. Segundo o relatório da World Intellectual Property Indicators (WIPO, 2019), o volume de depósitos de patentes no Brasil caiu pelo quinto ano consecutivo em 2019, e o país possui um dos mais altos volumes de análises pendentes entre os países de renda média (middle income countries), totalizando 196.354 solicitações. Essas pendências incluem documentos em qualquer estágio do processo, aguardando por uma decisão final (WIPO, 2019). Possivelmente, a morosidade do processo é um desestímulo ao patenteamento no país.

\section{Considerações Finais}

Na chamada era da informação, em que um alto volume de dados é gerado e com uma velocidade muito alta, conseguir analisar esses dados, transformando-os em conhecimento, se torna um grande diferencial competitivo para as empresas. Para empresas de base tecnológica, o desafio é ainda maior, e o desenvolvimento de metodologias para acompanhar os movimentos do mercado se torna essencial para mitigar riscos associados aos investimentos em Pesquisa $e$ Desenvolvimento.

O presente estudo apresentou a construção do Patent Landscape como uma importante ferramenta para construção de estratégia tecnológica e mercadológica, tendo sido aplicado em um tema de grande relevância: a destinação de resíduos de uma atividade agrícola em destaque no país: a produção de coco. 
Sob o aspecto mercadológico, foi possível depreender que o maior movimento mundial em prol do aproveitamento da fibra de coco está em linha com a região de maior produção, ou seja, se concentra na Ásia. Foi possível observar também que a partir de 2016, coincidindo com a queda da produção mundial de coco, houve uma queda na atividade patentária, podendo-se inferir que os dois eventos estão relacionados.

Sob o aspecto tecnológico, objetivando identificar a natureza das invenções e as principais tendências dos últimos anos, foi realizada análise com base no código CIP. Nesse ponto, a característica mais marcante foi o fato de que os grupos de maior recorrência nos documentos estão na Seção A - Necessidades Humanas, denotando um possível direcionamento para a aplicação final da fibra de coco, em detrimento da melhoria dos processos de sua obtenção, como já mencionado. A maior parte das patentes dizem respeito a desenvolvimento de colchões com fibra de coco em sua composição. Outros assuntos em destaque são a utilização da fibra como meio de cultivo e na constituição de mantas para proteção de solos e de corpos hidrográficos.

Outro aspecto que ficou marcado neste estudo foi que, apesar de o Brasil ter destaque no cenário internacional como produtor de coco, não foram identificadas na base internacional patentes concedidas para o aproveitamento do resíduo objeto deste trabalho, já mencionado também. Entre as patentes solicitadas, foram identificados três documentos, um deles com bastante aderência à tendência internacional voltada para meios de cultivos.

Frente ao exposto, considerando a tendência internacional mais marcante de desenvolvimentos voltados para atendimento do setor agrícola, bem como a posição de destaque do Brasil nessa atividade econômica, o estudo aponta uma importante janela de oportunidade, com ampla possibilidade de parcerias internacionais para desenvolvimento das inovações e capacidade de absorção das invenções pelo mercado interno. Essa indicação cumpre o propósito estratégico do estudo de patentes, podendo servir como direcionador para a academia $e$ as empresas na seleção de linhas de pesquisas ou novos negócios, por exemplo, ou ainda para o governo, para construção de políticas públicas.

Como sugestão de próximos estudos, corroborando para a formalização oportunidade identificada, propõe-se:

1. Análise do mercado brasileiro, validando a janela de oportunidade para o eixo tecnológico de maior demanda.

2. Mapeamento da capacitação tecnológica interna para desenvolvimento desse eixo tecnológico no país.

3. Proposição de políticas públicas voltadas para este fim, aproveitando as relações exteriores do país como meio de estabelecer parcerias com países/instituições já detentores de tecnologia.

\section{Referências}

BURTON, J. The World Leaders in Coconut Productio. [S.1.]: Diretório World Atlas, 2017.

Disponivel em: https:/www.worldatlas.com/articles/the-world-leaders-in- coconut-production.html. Acesso em: 8 fev. 2018.

CASTILHOS, L. F. F. de. Dossiê Técnico: aproveitamento da fibra de coco. Paraná: Instituto de Tecnologia do Paraná (TECPAR), 2011. 
DUPIN, L. C. O.; SPRITZER, A. A utilização de documentos de patente como fonte de informação tecnológica. [s.l.]: Congresso Brasileiro de Ensino de Engenharia, 2004.

EPO - EUROPEAN PATENT OFFICE. Annual Report 2018. [2019]. Disponível em https:// www.epo.org/about-us/annual-reports-statistics/annual-report/2018/statistics/patent-applications. html\#tab2. Acesso em: 18 mar. 2019.

FAOSTAT - FOOD AND AGRICULTURE ORGANIZATION. Base de dados estatísticos da produção mundial de grãos e alimentos. [2020]. Disponível em: http://www.fao.org/faostat/ en/\#data/QC. Acesso em: 20 abr. 2020.

GERHARDT, T. E.; SILVEIRA, D. T.; Métodos de pesquisa. Curso de Graduação Tecnológica Planejamento e Gestão para o Desenvolvimento Rural da SEAD/UFRGS. Universidade Aberta do Brasil - UAB/UFRGS. Porto Alegre: Editora da UFRGS, 2009.

INPI - INSTITUTO NACIONAL DA PROPRIEDADE INDUSTRIAL. Busca de Patentes. 2015. Disponível em: http://www.inpi.gov.br/menu-servicos/informacao/busca-de-patentes. Acesso em: 5 mar. 2019.

\section{IPEA - INSTITUTO DE PESQUISA ECONÔMICA APLICADA. Diagnóstico dos Resíduos} Orgânicos do Setor Agrossilvopastoril e Agroindústrias Associadas - Relatório de Pesquisa; Brasília, 2012. Disponível em: http://www.ipea.gov.br/portal/images/stories/PDFs/ relatoriopesquisa/120917_relator io_residuos_organicos.pdf. Acesso em: 5 mar. 2019.

MARTINS, A. P. Estudo sobre utilização de fibras de coco verde em estruturas têxteis. 2013. 132f. Dissertação (Mestrado) - Escola de Artes Ciências e Humanidades, Universidade de São Paulo, São Paulo, 2013.

MARTINS, C. R.; JESUS JR., L. A. de; Produção e Comercialização de Coco no Brasil Frente ao Comércio Internacional: Panorama 2014. Aracaju: Embrapa Tabuleiros Costeiros Aracaju, 2014.

MATTOS, A. L. A. et al. Beneficiamento da Casca de Coco Verde. Fortaleza: Embrapa; Agroindústria Tropical, 2014. Disponível em: http://www.ceinfo.cnpat.embrapa.br/arquivos/ artigo_3830.pdf. Acesso em: 8 fev. 2018

ONU - ORGANIZAÇÃO DAS NAÇÕES UNIDAS. Transformando Nosso Mundo: a Agenda 2030 para o Desenvolvimento Sustentável. Rio de Janeiro: ONU, 2015. Disponível em: https:// nacoesunidas.org/pos2015/agenda2030/. Acessado em: 18 fev. 2019.

PATENT INSPIRATION. Ferramenta de buscas de patentes. [2018]. Disponível em http://www. patentinspiration.com. Acesso em: 14 nov. 2018.

PEREIRA, C. L. Aproveitamento do resíduo do coco verde para produção de compósitos destinados à construção rural. 2012. 137f. Tese (Doutorado) - Faculdade de Zootecnia e Engenharia de Alimentos, Universidade de São Paulo, São Paulo, 2012.

ROSA, M. et al. Valorização de resíduos da agroindústria. In: II SIMPÓSIO INTERNACIONAL SOBRE GERENCIAMENTO DE RESÍDUOS AGROPECUÁRIOS E AGROINDUSTRIAIS - II SIGERA, Palestras, Paraná, 2011. Anais [...]. Paraná, v. I, p. 98-105, 2011.

SEBRAE NACIONAL. O cultivo e o mercado do coco verde. [2016]. Disponível em: http://www. sebrae.com.br/sites/PortalSebrae/artigos/o-cultivo-e-o-mercado-do-coco-verde,3aba9e665b182410V gnVCM100000b272010aRCRD. Acesso em: 8 fev. 2018. 
SOUZA, C. G. de; AGUIAR, R. A. A. de; MENDES, H. S. Como usar documentos de patentes como fonte de informação tecnológica. In: XXXVIII CONGRESSO BRASILEIRO DE EDUCAÇÃO EM ENGENHARIA (COBENGE 2010), Fortaleza, CE, 2010. Anais [...]. Fortaleza, CE, 2010.

TRIPPE, A. Guidelines for Preparing Patent Landscape Reports. [s.l.]: World Intellectual Property Organization, 2015.

WIPO - WORLD INTELLECTUAL PROPERTY ORGANIZATION. World Intellectual Property Indicators. Geneva: WIPO, 2019.

WIPO - WORLD INTELLECTUAL PROPERTY ORGANIZATION. International Patent Classification (IPC). [2018]. Disponível em: http://www.wipo.int/classifications/ipc/en/. Acesso em: 2 fev. 2018.

WIPO - WORLD INTELLECTUAL PROPERTY ORGANIZATION; INSEAD, Cornell University. Índice de Inovação Global 2017: Suíça, Suécia, Países Baixos, EUA e RU na Classificação Anual dos Melhores. Genebra, 2017. Disponível em: http:/www.wipo.int/export/sites/www/pressroom/en/ documents/gii_2017_pr-808-p.pdf. Acesso em: 16 jul. 2018.

\section{Sobre os Autores}

\section{Andrezza Lemos Rangel da Silva}

E-mail: andrezzalemos86@gmail.com

Mestre.

Endereço profissional: Av. Athos da Silveira Ramos, 149 - Cidade Universitária da Universidade Federal do Rio de Janeiro, Rio de Janeiro, RJ. CEP: 21941-909.

\section{Suzana Borschiver}

E-mail: suzana@eq.ufrj.br

Doutora.

Endereço profissional: Av. Athos da Silveira Ramos, 149 - Cidade Universitária da Universidade Federal do Rio de Janeiro, Rio de Janeiro, RJ. CEP: 21941-909.

\section{Ricardo Carvalho Rodrigues}

E-mail: ricardor@inpi.gov.br

Doutor.

Endereço profissional: Rua Mairink Veiga, n. 9, Centro, Rio de Janeiro, RJ. CEP: 20090-910. 